LA W RENCE LIVERMORE NATIONAL LABORATORY
Report on fact finding visit to Texas A\&M Cyclotron Institute

J. T. Burke, J. J. Ressler, N. D. Scielzo

July 16, 2011 
This document was prepared as an account of work sponsored by an agency of the United States government. Neither the United States government nor Lawrence Livermore National Security, LLC, nor any of their employees makes any warranty, expressed or implied, or assumes any legal liability or responsibility for the accuracy, completeness, or usefulness of any information, apparatus, product, or process disclosed, or represents that its use would not infringe privately owned rights. Reference herein to any specific commercial product, process, or service by trade name, trademark, manufacturer, or otherwise does not necessarily constitute or imply its endorsement, recommendation, or favoring by the United States government or Lawrence Livermore National Security, LLC. The views and opinions of authors expressed herein do not necessarily state or reflect those of the United States government or Lawrence Livermore National Security, LLC, and shall not be used for advertising or product endorsement purposes.

This work performed under the auspices of the U.S. Department of Energy by Lawrence Livermore National Laboratory under Contract DE-AC52-07NA27344. 


\title{
Report on fact finding visit to Texas A\&M Cyclotron Institute
}

\author{
J.T. Burke, J.J. Ressler and N.D. Scielzo - Lawrence Livermore National Laboratory
}

During the $3^{\text {rd }}$ quarter of FY11 the experimental nuclear group, involved in surrogate reactions research, visited Texas A\&M University Cyclotron Institute. Our mid-project "Schubert Review" called into concern the lack of a backup facility where our research may be performed should anything occur to disrupt operations at the 88 Inch Cyclotron at LBNL. To that end, Drs. N.D. Scielzo, J.J. Ressler, J.T. Burke and section leader Dennis McNabb visited the Texas A\&M Cyclotron Institute June $13^{\text {th }}$ and $14^{\text {th }}$.

The facility offers two machines from which accelerated beams can be extracted a K150 and a K500 cyclotron. The K150 is identical to the 88 Inch Cyclotron accelerator at Lawrence Berkeley National Laboratory. The K500 is a superconducting cyclotron capable of energies needed for inverse kinematics experiments, similar to the Facility for Rare Isotope Beams (FRIB) planned for Michigan State University. By partnering with Texas A\&M we will be able to position ourselves to perform experiments on short lived fission fragments and other exotic nuclei 5 years ahead of the anticipated FRIB start date. We will also be able to maintain our current capabilities as the facility has both low energy light ion and high energy heavy ion beams available, see Figure 1.

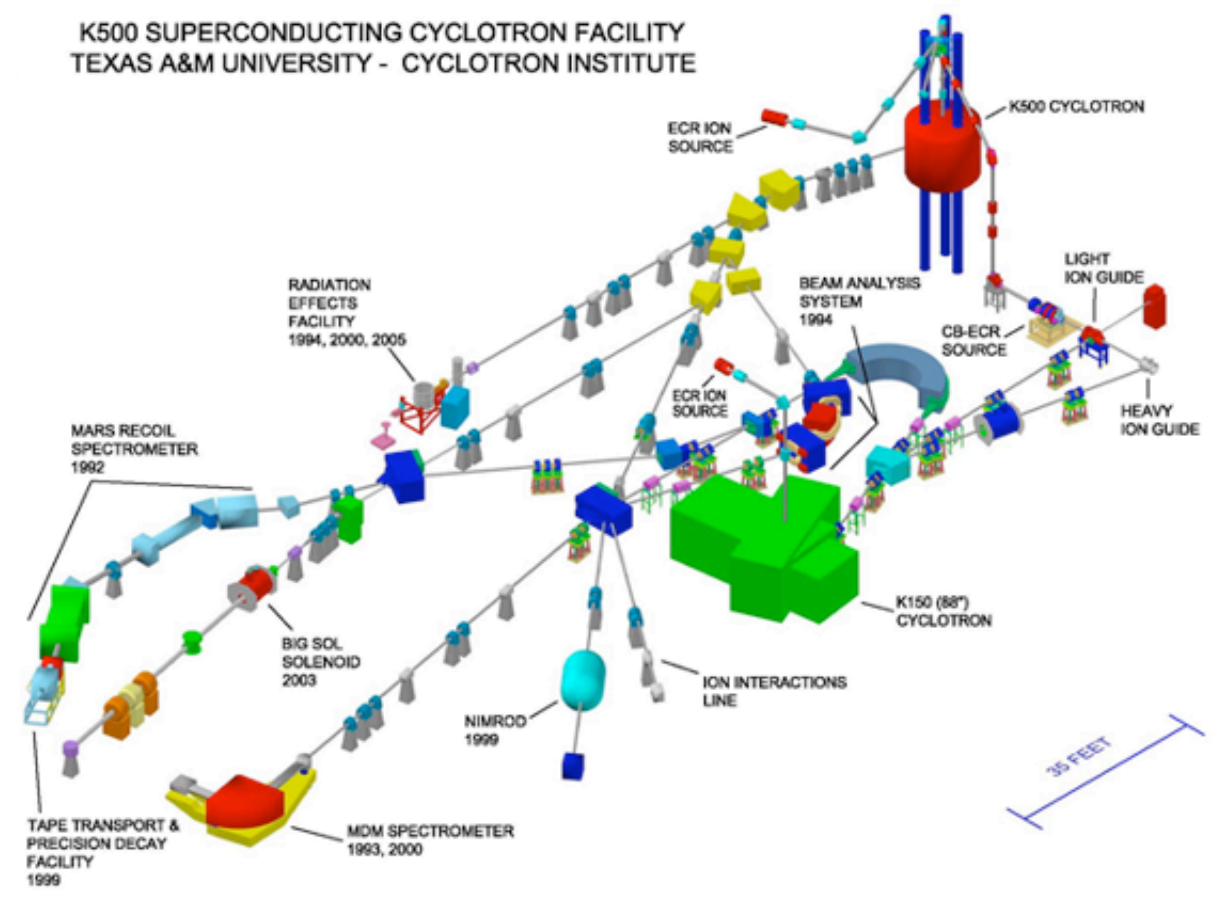

Figure 1. The Texas A\&M Cyclotron Institute maintains two separate accelerators shown here as K150 and K500. Note that almost all the beam lines finish at target stations where beams can be supplied from either accelerator. 
The facility has over 60 students, faculty and technical staff maintaining operations and conducting research. We identified several beam lines where we would be able to position our detector arrays. We found the staff and technical personnel to be very interested in having us involved with their facility.

Specifically we identified a potential position for the ORRUBA array from our colleague Professor Jolie Cizeswki on the MDM spectrometer beamline, see figure 2. The beamline position has already been used for nuclear physics experiments and has optics in place to focus the beam with the necessary qualities to perform experiments. Talks are underway with Professor Cizewski concerning partnering with Texas A\&M.

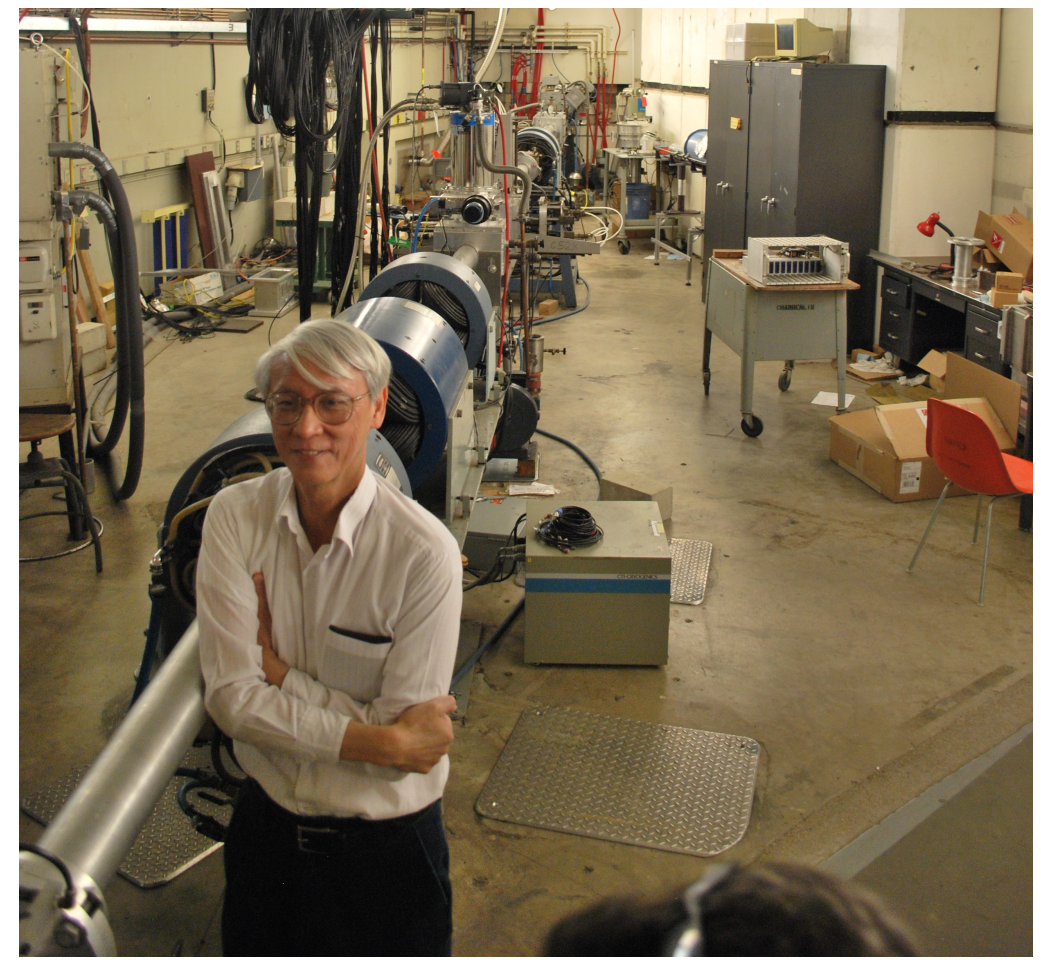

Figure 2. Dr. Lui standing beside the beamline for the MDM spectrometer. Just upstream of his position there is an 8 foot section of beamline that can be removed to allow the insertion of a detector array.

On the Ion Interactions Line, currently hosting an old atomic physics apparatus, there is room to put the STARS/Liberace array or a suitable copy of it. If we relocate the current STARS/Liberace chamber back into Cave 4C at LBNL, then we could bring our current stand and literally drop it in place on the Ion Interactions Line, see figure 3. The beamline height at Texas A\&M (throughout the facility) is 48 inches from the floor, which is exactly the beam line height at the 88 Inch Cyclotron at LBNL making the transition nearly seamless. 


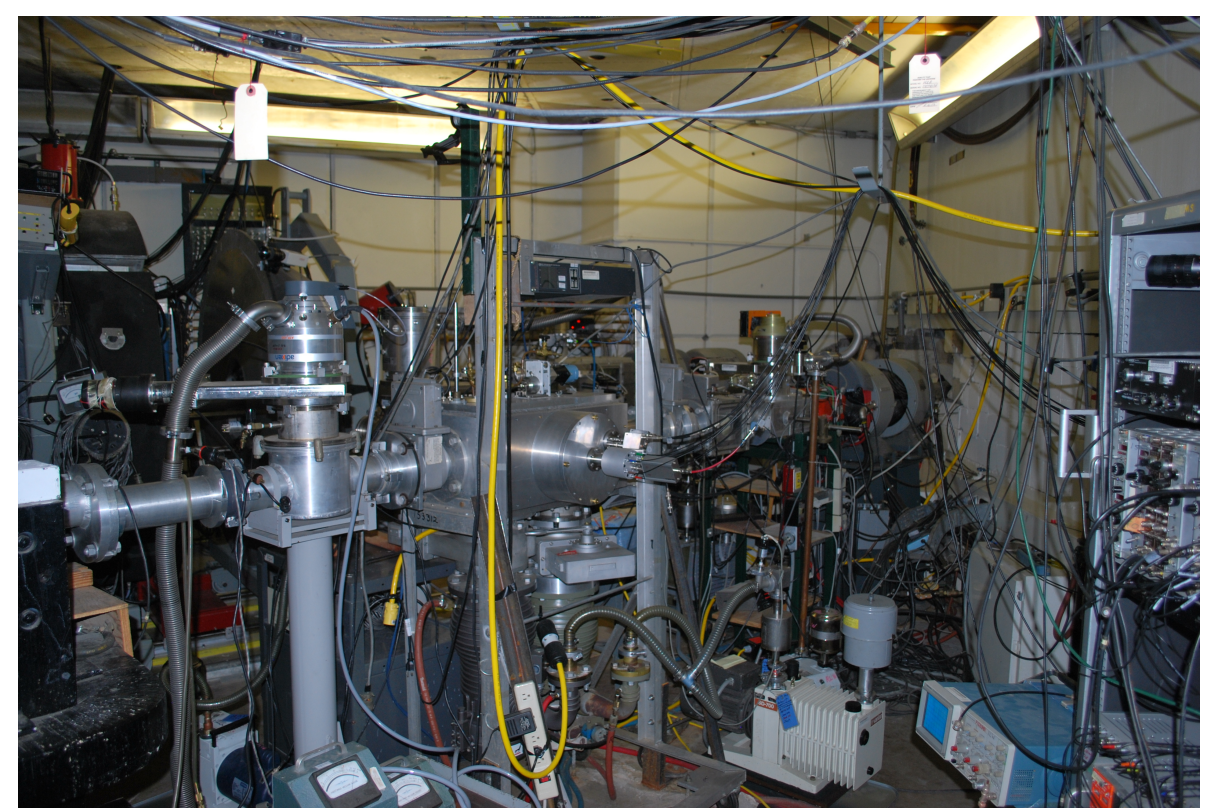

Figure 3. Ion Interactions Line with older atomic physics apparatus.

Lastly, the MDM spectrometer beamline has a large particle scattering chamber located around the target focal point, see figure 4. This scattering chamber is a near duplicate of the HYDRA chamber we have developed for our research at LBNL. However the beamline optics and energy resolution from the high energy resolution beam analysis system offers us better energy resolution and focus than we currently have. The beam qualities coupled with the scattering chamber and magnetic spectrometer would open up new opportunities to measure detailed particle scattering cross sections. This would help guide reaction theory for surrogate reactions as well as for experiments to be planned at FRIB in the future.

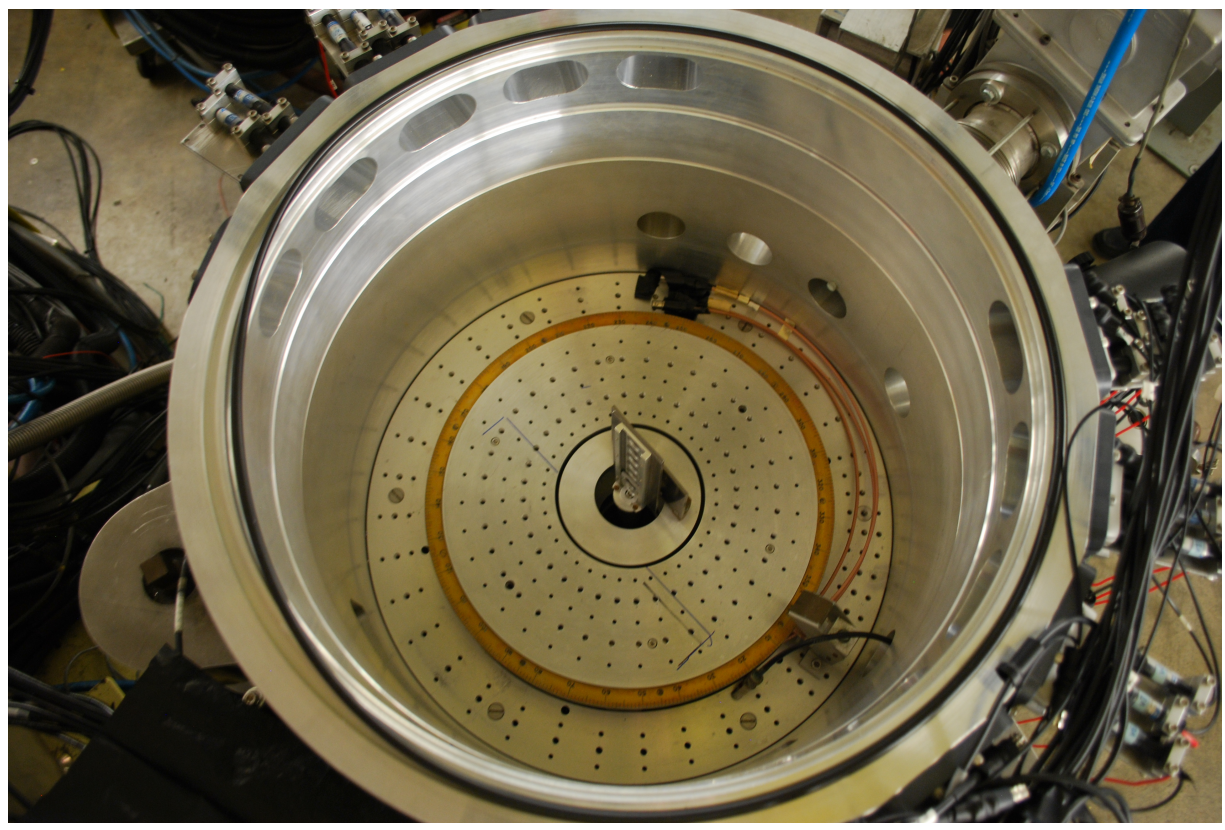


Figure 4. The MDM scattering chamber. The chamber contains a series of screw hole marked off at 10 degree increments to which one can mount detectors. The target ladder in the center of the chamber can mount multiple targets including tuning elements.

\section{Summary:}

I am actively investigating how to form a larger collaboration that will include Texas A\&M as a key partner. The Institute currently has thousands of hours of beam time available for experiments per year. The facility is well staffed at the technical and engineering levels and hosts a large complement of undergraduate students, graduate students and post-doctoral researchers. I have also discovered that the NNSA has a matching program to help foster University-LLNL partnerships. There is currently up to $\$ 125 \mathrm{k}$ of matching funds available at LLNL available for collaborative research. A Texas A\&M-LLNL collaboration would allow us to build a strong pipeline of students and researchers into the NNSA laboratories. We would also be able to have multiple students, post-docs and researchers involved and potentially lead some of the many experiments we need done to perform for our research programs.

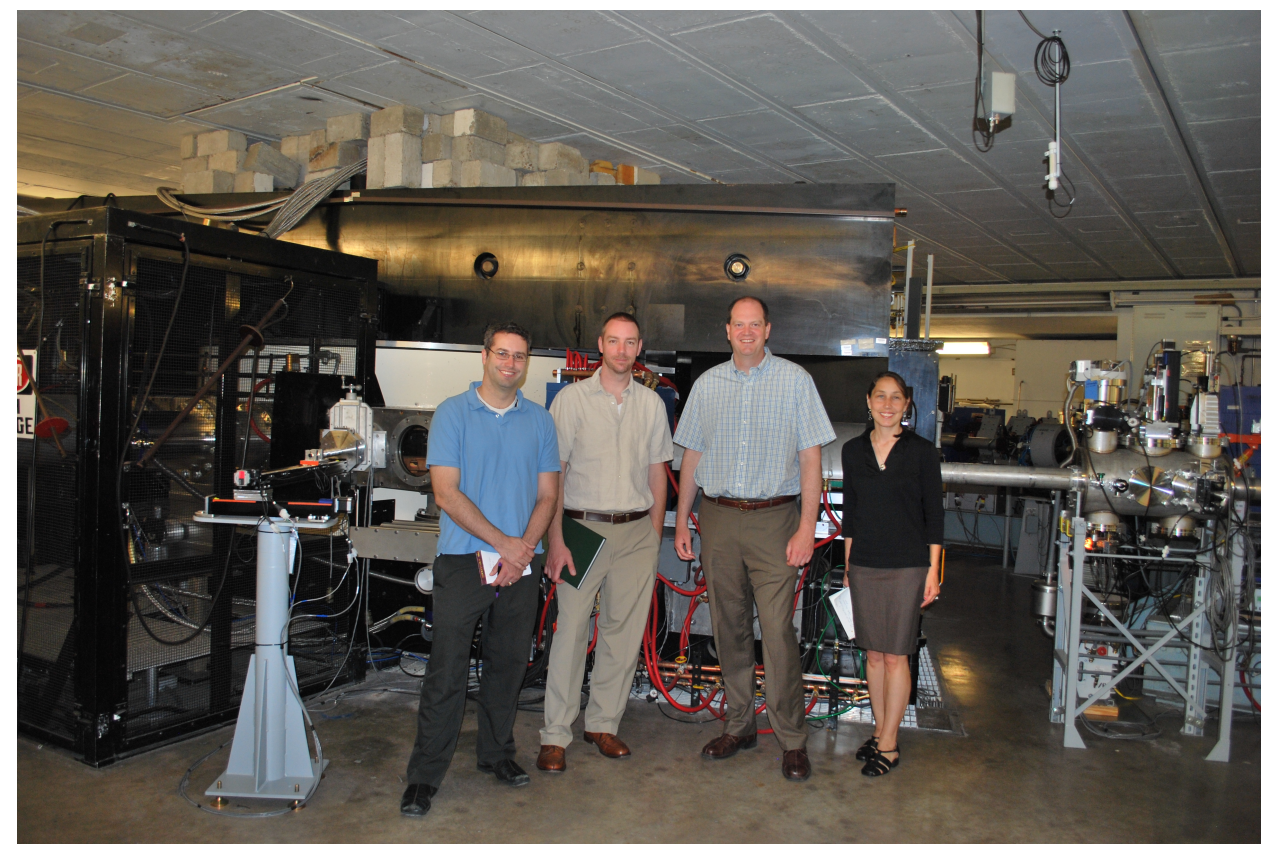

Figure 5: From left to right are Dr. Sciezo, Dr. Burke, Dr. McNabb and Dr. Ressler standing in front of the 88 Inch Cyclotron at the Texas A\&M Cyclotron Institute. The large solid black object is the iron yoke of the Texas A\&M K150 cyclotron. To Dr. Ressler's left is the beamline at the exit of the cyclotron. 